\title{
A JUdiCIALIZAÇÁO DAS \\ POLÍTICAS PÚBLICAS E O DIREITO \\ À EDUCAÇÃO INFANTIL
}

\section{The JUdiCIALIZATION OF PUBLIC POLICIES AND THE RIGHT TO CHILD EDUCATION}

\author{
Barbara Cristina Hanauer Taporosky \\ Mestre em educação pela Universidade Federal do Paraná, Curitiba, Paraná, Brasil. \\ ORCID: http://orcid.org/0000-0002-8251-6005 \\ barbara86ha@yahoo.com.br
}

Adriana Dragone Silveira

Doutora em educação pela Universidade de São Paulo. Professora do Departamento de Planejamento Escolar da Universidade Federal do Paraná, Curitiba, Paraná, Brasil. ORCID: http://orcid.org/0000-0001-6022-627X

adrianadragone@yahoo.com.br

Resumo: O presente artigo propóe uma discussão a respeito do tema da judicialização das políticas públicas a partir do direito à Educação Infantil, com o objetivo de analisar conceitos e conteúdos constantes na produção bibliográfica relacionados à temática. A partir da produçáo existente sobre tema, discute os conceitos de justiciabilidade do direito e judicialização, suas causas e principais obstáculos, dentre os quais o princípio da separação dos poderes, a discricionariedade administrativa e a teoria da reserva do possível. Discute, ainda, a noção do mínimo existencial e as possibilidades de interferência do Poder Judiciário nas políticas educacionais, concluindo por sua necessidade nos casos em que o direito à Educação Infantil não é garantido pelos demais poderes. Aponta, por fim, a necessidade de pesquisas empíricas que possam averiguar quais os limites à atuação do Poder Judiciário nas políticas educacionais.

Palavras-chave: Direito à Educação. Educação Infantil. Judicialização. Políticas Educacionais.

Aвstract: This article proposes to conduct a discussion on the topic of the judicialization of public policies based on the right to early childhood education, with the objective of analyzing concepts and contents, included in the bibliographic production related to the theme. From the existing production on the subject, it discusses the of justiciability of the law and judicialization, its causes and main obstacles, among which the principle of separation of powers, administrative discretion and the theory of the reserve of the possible. It also discusses the notion of the existential minimum and the possibilities of interference of the Judiciary in educational policies, concluding for its necessity in cases where the right to early childhood education is not guaranteed by the other Powers. 
Finally, it points out the need for empirical research that can ascertain the limits to the Judiciary's performance in educational policies.

Keywords: Right to Education. Early Childhood Education. Judicialization. Educational Policies.

\section{Introduçáo}

O direito à educação está previsto na Constituição da República Federativa do Brasil (CF/88) como direito social fundamental (art. 6o) e, como tal, requer a criação de políticas públicas para sua efetivação (DUARTE, 2004). A CF/88 prevê a obrigatoriedade de o Estado promover a Educação Infantil em creche e pré-escola (BRASIL, 1988). Trata-se de um direito das crianças de zero a cinco anos ${ }^{1}$ de idade, também previsto no art. $4^{\circ}$, II, da Lei de Diretrizes e Bases da Educação Nacional (LDB 9.394/1996). É a primeira etapa da Educação Básica (BRASIL, 1996) e visa o desenvolvimento integral das crianças. Também é prevista como direito dos trabalhadores, conforme art. 7o, XXV, da CF/88. (BRASIL, 1988)

$\mathrm{O}$ reconhecimento do direito à educação enquanto um direito social humano e fundamental é fruto de um processo de lutas e conquistas. para a proteçáo do homem frente às ameaças que sofre com o desenvolvimento da sociedade (BOBBIO, 1992). Enquanto direito social, visa a redução das desigualdades, igualando o status dos indivíduos (MARSHAL, 1967; SADEK, 2013), configurando-se, ainda, como um fim social no ordenamento jurídico brasileiro, o que garante seu atendimento com a máxima prioridade (ZANETI JUNIOR. 2013; JACOB, 2013). A ausência de sua prestação pelo Poder Público ou sua prestação de forma desigual configura sua violação, sendo possível exigi-lo do Estado inclusive perante o Poder Judiciário (LOPES, 2002; ABRAMOVICH, 2005), o que implica em sua justiciabilidade - conceituada como a capacidade de se exigir sua garantia junto ao Poder Judiciário, quando não atendido adequadamente pelos poderes competentes (PANNUNZIO, 2009). "Este reconhecimento implica na obrigaçáo do poder público de garantir a educaçáo visando a igualdade das pessoas e, por outro lado, garante ao interessado o poder de buscar no judiciário a sua concretização.” (CURY; FERREIRA, 2010) 
Esse estatuto de fundamentalidade dos direitos sociais e, em particular, do direito à educação, atribui-se também ao direito à Educação Infantil. Historicamente deixada ao encargo dos órgãos de assistência social, esse nível educacional apenas foi reconhecido como direito das crianças e dos trabalhadores na $\mathrm{CF} / 88$, após diversas lutas e reivindicaçôes populares de diferentes atores sociais. A LDB integrou-a como etapa educacional, reafirmando a gratuidade prevista na Constituição (CURY, 1998). Essas previsóes legais foram corroboradas pelo Estatuto da Criança e do Adolescente (BRASIL, 1990), reforçando-se que a educação infantil deve ser atendida com absoluta prioridade (SILVEIRA, 2014), e pelo Marco Legal da Primeira Infância, que prevê a Educação Infantil como uma das áreas prioritárias para a infância (BRASIL, 2016c).

Reconhecer a educação infantil enquanto um direito significa dizer que é dever do Estado garanti-la (RIZZI; XIMENES, 2010). Contudo, segundo dados de 2014 do Instituto Nacional de Estudos e Pesquisas Educacionais Anísio Teixeira (INEP), 89,6\% das crianças entre quatro e cinco anos frequentavam a pré-escola e $33,3 \%$ das crianças entre zero e três anos frequentavam a creche (BRASIL, 2016a), o que indica a necessidade de expansão dessa etapa da educação, dado o fato de que tal direito não tem sido efetivado para todos. Até o ano de 2005 haviam decisóes judiciais indicando que a educação infantil não se tratava de um dever do Estado, estando o acesso limitado às vagas disponibilizadas, conforme demonstram, por exemplo, as pesquisas de Rizzi e Ximenes (2010), Silveira (2010), Graciano, Marinho e Fernandes (2006) e Marinho (2009).

No entanto, no ano de 2005, o Supremo Tribunal Federal (STF), no julgamento do Recurso Extraordinário no 436.996, reconheceu o dever do Poder Público de ofertar vagas na Educação Infantil a todas as crianças de até seis anos de idade que assim necessitassem, sendo dever da Administração a disponibilização de vagas de acordo com a procura (BRASIL, 2005). Essa decisão serviu como precedente para as decisóes proferidas em casos semelhantes a contar daquela data.

A justiciabilidade, portanto, do direito à Educação Infantil, aliada a outros fatores, acabou colocando em curso, em todo o Brasil, diversas açóes visando justamente a obtençáo de vagas na creche e na pré-escola (SILVEIRA, 2014). Dessa forma, diversas vagas foram e são abertas em virtude de decisóes judiciais que assim determinam. Uma vez que o Estado 
concretiza os direitos sociais por meio da implantação de políticas públicas (DUARTE, 2004; DUARTE, 2006), descumprido esse dever estatal, é direito do cidadáo requisitar seu cumprimento, quer individualmente quer coletivamente, perante o Poder Judiciário, inclusive no âmbito do direito à educação: "A ausência de política pública que garanta o processo educacional, realizada de forma sistemática pela escola, acaba por acarretar medidas judiciais que interferem no cotidiano educacional." (CURY; FERREIRA, 2010, p. 101) Por vezes, esses questionamentos levados ao conhecimento do Poder Judiciário acabam gerando a interferência desse Poder nas políticas. Quando essa interferência de atores do sistema de justiça acaba modificando a política pública, ou deslocando as discussóes a seu respeito para essa esfera, ocorre o fenômeno da judicialização. (TATE; VALLINDER, 1995; BARROSO, 2009; SILVEIRA, 2013; SOUSA SANTOS, 2011)

Dessa forma, apresentam-se como relevantes as pesquisas que se prestem a investigar esse fenômeno, como apontado por Machado e Oliveira (2001), Silveira (2008) e Feldman e Silveira (2017). Ainda Barreiro e Furtado (2015) esclarecem que se faz necessário um aprofundamento nos estudos que relacionam a judicialização com as políticas públicas, uma vez que o Poder Judiciário tem substituído os demais poderes na formulação

\section{A judicialização das políticas públicas}

A judicialização é um fenômeno que vem ocorrendo em muitos países democráticos e, embora suas causas variem de país para país, é possível encontrar algumas determinantes gerais. Tate e Vallinder (1995) apresentam como condiçóes necessárias à judicializaçáo: a democracia, a separação dos poderes, os direitos políticos, o uso dos tribunais pelos grupos de interesse e pela oposição e a inefetividade das instituições majoritárias. Sousa Santos (2011), por sua vez, ressalta que uma das causas da inter- 
ferência do Poder Judiciário reside na ausência da realização, pelo Poder Executivo das prestaçôes sociais que compóem seu âmbito de dever legal.

Existe ainda um questionamento a respeito da possibilidade de decisões tomadas por políticos eleitos democraticamente serem substituídas por decisóes vindas das cortes judiciais (TATE; VALLINDER, 1995). Isso porque a escolha de priorizar determinado direito ou buscar um fim constitucional específico nada mais é do que uma decisão política (VIOLIN, 2012). Mas a questáo reside também em verificar se o Poder Executivo tem liberdade para realizar os fins constitucionais que necessitam de políticas públicas para seu atendimento, optando por uns em detrimento a outros.

A efetivação dos direitos sociais, mediante a realização de políticas públicas, depende de um conjunto de atos que são próprios aos poderes Executivo e Legislativo, tais como leis que prevejam o programa necessário à sua concretização, orçamento - para o qual são necessárias leis prevendo a despesa e sua execução pelo Poder Executivo -, além de todos os atos administrativos necessários à sua execução (LOPES, 2002). No entanto, uma decisão judicial de controle sobre determinada política pública não necessariamente invalida ou controla os atos que a compóem. (COMPARATO, 1998)

Há, assim, diversos argumentos contrários à judicialização da política e, especialmente, das políticas de Educação Infantil. Dentre os principais, encontram-se a afronta ao princípio da separação dos poderes, a discricionariedade administrativa e a teoria da reserva do possível, como apontados nas pesquisas de Silveira (2014), Corrêa (2014), Silveira (2015) e Scaff e Pinto (2016).

Afigura-se importante afirmar que a legitimidade democrática do Poder Judiciário reside na própria constituição e nas leis (VIOLIN, 2012; ZANETI JUNIOR, 2013). Todo o Poder é uno e "emana do povo", conforme prevê o art. $1^{\circ}$, parágrafo único, da $\mathrm{CF} / 88$, "sendo apenas distribuídas as funçóes pelos diversos órgáos do Executivo, do Legislativo e do Judiciário." (ZANETI JUNIOR, 2013, p. 50). Dessa forma, tem o Poder Judiciário força, na Constituição, para controlar questóes que estão ao seu alcance nos termos do ordenamento jurídico brasileiro.

Sendo assim, serão analisados na sequência dois pontos apresentados como obstáculos, nos processos judiciais, ao controle judicial das políticas 
de Educação Infantil: o princípio da separação dos poderes, a partir do qual se discutirá a discricionariedade administrativa, e a teoria da reserva do possível, que como já apontado trata dos principais argumentos utilizados pela Administração para invocar a impossibilidade de interferência do Poder Judiciário nas políticas de Educação Infantil.

\section{O princípio da separaçáo dos poderes}

Previsto na CF/88 em seu artigo 20 (BRASIL, 1988), disciplina que cada um dos três poderes (Executivo, Legislativo e Judiciário) possui funçóes próprias a eles inerentes e que existem limites para o exercício de um Poder sobre o outro, havendo situaçóes que não são passíveis de controle externo (JACOB, 2013). Em sua concepção clássica, esse princípio foi erigido em torno da lei: um Poder a faz, outro a aplica e o terceiro aplica contenciosamente (FERREIRA FILHO, 1994). Caberia ao Poder Judiciário o controle da correta aplicação da lei, sendo o juiz um personagem neutro a quem é conferida a função de "boca da lei" (SADEK, 2013, p. 11). Jacob (2013, p. 239) defende que "se faz imperiosa a delimitação dos controles a fim de evitar a intromissão de um no que se poderia chamar de núcleo essencial do outro." Daí surgem as alegações de que o Poder Judiciário, ao efetuar o controle das políticas públicas, ofenderia ao princípio da separação dos poderes, mediante ingerência em atividade eminentemente administrativa.

Contudo, há uma interação e complementaridade no exercício das funçôes do Estado quando esse princípio é interpretado conjuntamente aos demais preceitos constitucionais. A Constituição prevê a proteção dos direitos fundamentais, inclusive conferindo-lhes o status de cláusula pétrea $^{2}$; sendo assim, o princípio da separação dos poderes também está vinculado à proteção máxima desses direitos (ARAÚJO, 2013). É “mais apropriado se falar em noçóes de colaboração, harmonia e independência orgânica dos poderes" (VICTOR, 2011, p. 1), conforme a previsão inserta no art. 2o da CF/88 (BRASIL, 1988). "Logo, os três poderes devem harmonizar-se para que os objetivos fundamentais do Estado sejam alcançados." (GRINOVER, 2013, p. 128) 
Taylor (2007) esclarece que a forma como os Poderes estão disciplinados na $\mathrm{CF} / 88$ indica que há uma sobreposição de suas funçôes, conforme se verifica no Quadro 1.

\begin{tabular}{|c|c|c|c|}
\hline \multicolumn{4}{|c|}{ Instituição } \\
\hline Função & Congresso & Executivo & Judiciário \\
\hline Legislativa & Faz leis. & $\begin{array}{l}\text { Recomenda leis; } \\
\text { veta leis; cria } \\
\text { regulamentos e } \\
\text { medidas provisórias } \\
\text { com força de leis. }\end{array}$ & $\begin{array}{l}\text { Revisa as leis para } \\
\text { determinar ou } \\
\text { julgar a intenção } \\
\text { legislativa. }\end{array}$ \\
\hline Executiva & $\begin{array}{c}\text { Derruba vetos } \\
\text { presidenciais; veta } \\
\text { medidas provisórias. }\end{array}$ & $\begin{array}{c}\text { Aplica e } \\
\text { implementa as leis. }\end{array}$ & $\begin{array}{l}\text { Revisa os atos } \\
\text { executivos; restringe } \\
\text { as açóes executivas } \\
\text { por via de liminar. }\end{array}$ \\
\hline Judicial & $\begin{array}{l}\text { Propõe e julga processos } \\
\text { de impeachment; } \\
\text { instaura Comissóes } \\
\text { Parlamentares de } \\
\text { Inquérito. }\end{array}$ & $\begin{array}{c}\text { Nomeia ministros } \\
\text { (com subsequente } \\
\text { aprovação } \\
\text { legislativa). }\end{array}$ & $\begin{array}{c}\text { Interpreta e julga a } \\
\text { constitucionalidade } \\
\text { das leis. }\end{array}$ \\
\hline
\end{tabular}

\section{Quadro 1: A distribuição das funções}

Fonte: TAYLOR (2007, p. 250)

De acordo com a prescrição constitucional de funçóes para cada um dos três poderes, sobrepóem-se a todos funçóes legislativas, executivas e judiciais. Embora haja para cada Poder correlato a preponderância no exercício de uma dessas funçóes, não é possível dizer que as mesmas são exclusivas de apenas um deles. O próprio controle da constitucionalidade das leis previsto na Constituição já indica a possibilidade de controle, pelo Judiciário, dos atos dos demais poderes (WATANABE, 2013) que, conforme apontado por Vallinder (1995), também se trata de uma forma de judicialização. Isso não significa que o Judiciário irá atuar diretamente, ou usurpar as funçôes próprias dos demais Poderes. Mas, nesse aspecto, prevê que é dever do Judiciário exercer a funçáo de proteger os direitos fundamentais mediante o controle dos atos exercidos tanto pelo Executivo quanto pelo Legislativo, caso esses atos se desviem dos fins constitucionais 
propostos, especialmente considerando que a Constituição é voltada à concretização de seus fins sociais, que em determinados casos só é possível por meio de políticas públicas eficazes. (ARAÚJO, 2013)

A própria $\mathrm{CF} / 88$ prevê que cabe ao Poder Judiciário o controle de qualquer ameaça ou lesão a direito (art. 5º, XXXV) (BRASIL, 1988). Portanto, todo e qualquer ato, quer seja comissivo quer seja omissivo, realizado por outros poderes que dificulte ou impeça o exercício pleno de um direito pelo particular pode ser objeto de controle judicial (VICTOR, 2011). Silveira (2013) ressalta que, nessa ótica, não se trata de ingerência do Poder Judiciário sobre outros poderes, mas sim de cumprimento de sua funçâo constitucional. Nâo foge, portanto, da alçada do Poder Judiciário o controle das políticas públicas, uma vez que as mesmas são meios de efetivação de direitos fundamentais. Como consequência, havendo lesão a direito fundamental, cabe ao Judiciário a interferência nas políticas públicas. (CANELA JUNIOR, 2013)

É certo que há, nos demais poderes, um âmbito de discricionariedade próprio ao exercício de suas funções. Inclusive o campo das políticas públicas é justamente o "ambiente da discricionariedade administrativa." (DANIEL, 2013, p. 113) A discricionariedade é o Poder que o administrador possui para atuar livremente, dentro dos limites legais: "[...] a lei deixa certa margem de decisão diante do caso concreto, de tal modo que a autoridade poderá optar por uma dentre várias soluçôes possíveis, todas válidas perante o direito." (PIETRO, 2001, p. 196) O exercício dessa discricionariedade náo pode impedir ou atrapalhar o exercício dos direitos fundamentais - sendo que, nesse caso, abre-se a possibilidade da interferência do Judiciário, como defendido até aqui (ZANETI JUNIOR, 2013). A discricionariedade não atribui total liberalidade para que o administrador realize as políticas públicas como bem desejar, ainda que seja ele quem melhor conheça a realidade administrativa e financeira do ente (DANIEL, 2013).

Nesses termos, a Educação Infantil, como política pública essencial ao atendimento das necessidades das crianças, deve ser entendida como de absoluta prioridade e, portanto, não se trata de discricionariedade, mas efetivo dever do Poder Público (SILVEIRA, 2014). Esse mesmo autor pontua que havia decisóes exaradas pelo TJSP reconhecendo a discricionariedade do Poder Público na oferta da Educação Infantil. Essa situação foi modi- 
ficada quando o STF se pronunciou no sentido de confirmar a interpretação de que a oferta da educação infantil constitui dever do Estado e não compóe o âmbito de discricionariedade administrativa, como visto sendo reconhecido como verdadeiro direito público subjetivo (BRASIL, 2005) O STF, aliás, reconheceu que a vinculação constitucional dos municípios à oferta da Educação Infantil representa um limitador de sua discricionariedade, por se tratar sua oferta de norma vinculante ao Poder Público. (BRASIL, 2006)

No entanto, isso não impede que se reconheça que há limites também ao Poder Judiciário (SILVEIRA, 2013), pelo entendimento de que há funçôes que são específicas de cada ente estatal. Nessa seara, "não é tarefa da alçada do Judiciário definir políticas públicas, tampouco substituir o administrador na escolha das prioridades orçamentárias" (DANIEL, 2013, p. 119), motivo pelo qual não é autorizado a esse Poder sobrepor-se aos demais sob a alegação de estar exercendo legítimo controle judicial.

Essa concepção foi adotada e aplicada ao direito à Educação Infantil pelo STF no julgamento do RE 436.996, ao esclarecer que, embora a elaboração e implementação de políticas públicas seja função própria dos poderes Executivo e Legislativo, cabe ao Judiciário tal incumbência quando a ação ou omissão daqueles poderes comprometerem a efetivação dos direitos dotados de envergadura constitucional. (BRASIL, 2005)

Realizada a discussão relativa ao princípio da separação dos Poderes, bem como sua aplicabilidade nos casos em que se discute judicialmente o direito à Educação Infantil, passa-se a abordar uma segunda limitação apresentada ao seu controle judicial: a teoria da reserva do possível.

\section{A teoria da reserva do possível}

Essa teoria tem sua origem na Alemanha, na década de 1970, preconizando que "a efetividade dos direitos fundamentais sociais dependeria da disponibilidade financeira do Estado.” (CANELA JUNIOR, 2013, p. 232) Nesses termos, não havendo previsão orçamentária, não poderia o Judiciário determinar a realização da política, em virtude da ausência de recursos a viabilizarem seu cumprimento, especialmente ante as limita- 
ções próprias dos orçamentos (SILVEIRA, 2013). A reserva do possível, portanto, constituiria limite fático e jurídico ao cumprimento dos direitos fundamentais (SARLET, 2008). Contudo, como ressalta Ximenes (2014, p. 156), essa impossibilidade deve ser demonstrada objetivamente, assumindo "o ônus probatório da ausência de condiçóes materiais para implementaçáo do direito em questão."

Tendo em vista que a realização de políticas públicas como forma de satisfazer os direitos sociais exige a alocação de recursos por parte do Estado, a teoria da reserva do possível pode se constituir tanto como um limite fático - inexistindo recursos em caixa não é possível realizar qualquer investimento -, quanto jurídico - o recurso existe, mas na previsão orçamentária o legislador o destinou para a efetivação de algum outro direito. Com relação ao primeiro limitador, o STF sinalizou, em decisão monocrática proferida no ano de 2004, no julgamento da Arguição de Descumprimento de Preceito Fundamental (ADPF) no 45, que poderia se constituir em um argumento válido quando, de fato, inexistem os recursos (BRASIL, 2004). No entanto, esse argumento tem sido utilizado de forma genérica para justificar o descumprimento dos direitos fundamentais sociais. (SARLET, 2008)

É necessário, portanto, problematizar a questão: se o recurso existe, uma decisão política em relação à alocação dos recursos que, caso não contemple como prioridade a efetivação dos direitos sociais, não realiza as metas insertas no texto constitucional (JACOB, 2013). Trata-se de opção política dos demais poderes que contraria a Constituição. Considerando isso, o reconhecimento da aplicabilidade da teoria da reserva do possível iria de encontro com a noção de que o orçamento público deve ser realizado visando a consecução dos fins sociais insertos no art. $3^{\circ} \mathrm{da} C F / 88$ (CANELA JUNIOR, 2013). Jacob (2013) ainda ressalta que os direitos sociais estão devidamente delineados como prioritários na Carta Magna, tendo o constituinte, inclusive, apontado os caminhos a serem seguidos e a disponibilidade orçamentária a eles vinculada, em diversos casos. Portanto, não se afigura razoável decisões de política orçamentária que não prevejam o cumprimento prioritário dos direitos sociais.

Nessa ótica, portanto, a reserva do possível não seria oponível ao direito à Educação Infantil quando os recursos existentes são destinados a 
rubricas diversas, uma vez que o próprio STF a reconheceu como objetivo constitucional, tratando-se de "um nítido programa a ser implementado mediante adoção de políticas públicas conseqüentes e responsáveis" (BRASIL, 2006, p. 1536-1537, grifos no original), devendo ser preservado enquanto mínimo existencial. A noção do mínimo existencial trata dos direitos fundamentais que compóem o núcleo básico para garantir a dignidade do cidadáo (WATANABE, 2013; SARLET; SAAVEDRA, 2012), abaixo do qual haveria sua flagrante violação (HEUKO, 2012). Nesses casos, a reserva do possível não poderia se opor à imediata satisfação do direito. (GRINOVER, 2013)

Também de origem alemã e surgida no início da década de 1950, o mínimo existencial contempla a ideia de que "sem os recursos materiais para uma existência digna, a própria dignidade da pessoa humana ficaria sacrificada" (SARLET; SAAVEDRA, 2012, p. 73), não apenas como um instituto de defesa, mas também como um direito às prestaçóes positivas necessárias à garantia da vida. Portanto, o mínimo existencial corresponderia às condiçóes mínimas que deveriam ser atendidas pelo Estado para a garantia da existência digna do cidadão e para sua integração na sociedade (SARLET; FIGUEIREDO, 2013). Sarlet e Figueiredo (2013) esclarecem que o mínimo existencial não está vinculado apenas à superação do limite da pobreza absoluta, o que também é defendido por Sarlet e Saavedra (2012), sendo necessário assegurar a plena fruição dos direitos fundamentais e o pleno desenvolvimento da personalidade: "Não deixar alguém sucumbir à fome certamente é o primeiro passo em termos de garantia de um mínimo existencial, mas não é - e muitas vezes não o é sequer de longe - o suficiente." (SARLET; FIGUEIREDO, 2013, p. 23)

A grande controvérsia reside em compreender o que integraria o chamado mínimo existencial. Não há uma concordância entre os estudiosos do tema, apenas o reconhecimento de sua vinculação à dignidade da pessoa humana (ARAÚJO, 2013). Sarlet e Figueiredo (2013) esclarecem que ele deve guardar relação com a compreensão constitucional do necessário para garantia da vida e da dignidade da pessoa humana, o que corresponde à garantia de uma "vida saudável" (SARLET; SAAVEDRA, 2012, p. 24). Indicando que o mínimo existencial deve ser identificado como o conteúdo essencial a ser protegido em determinado contexto, Ximenes (2014, p. 155, grifos no original) pondera: 
Não há, nesse sentido, um conteúdo mínimo existencial absoluto do direito fundamental reconhecido na forma de princípio, mas tão somente um conteúdo essencial protegido em determinado contexto, situado em algum ponto do longo caminho entre o direito em si e o direito definitivo e sendo movido por estratégia de progressiva delimitação. Ou seja, a não ser que por mínimo existencial se entenda o mesmo que conteúdo essencial, no sentido ora proposto, não haveria diferença conceitual relevante entre esses conceitos.

Muitas vezes, os próprios direitos sociais indicam dimensóes do mínimo existencial, embora não possam ser a ele reduzidos. Contudo, "tal constatação não afasta a circunstância de que, quando for o caso, este próprio conteúdo existencial (núcleo essencial = mínimo existencial) não é o mesmo em cada direito social [...]" (SARLET; FIGUEIREDO, 2013, p. 26).

Em vista disso, surge o questionamento de qual conteúdo do direito à educação comporia o mínimo existencial. Segundo Duarte (2004) e Watanabe (2013), o mínimo existencial no caso do direito à educação estaria limitado à Educação Básica obrigatória, o que excluiria a creche desse âmbito de proteção. No entanto, como apontam Sarlet e Figueiredo (2013, p. 26-27),

[...] a impossibilidade de se estabelecer, de forma apriorística e acima de tudo de modo taxativo, um elenco dos elementos nucleares do mínimo existencial, no sentido de um rol fechado de posiçôes subjetivas negativas e positivas correspondentes ao mínimo existencial. [...] O que compõe o mínimo existencial reclama, portanto, uma análise (ou pelo menos a possibilidade de uma averiguaçáo) à luz das necessidades de cada pessoa e de seu núcleo familiar, quando for o caso. Tudo isso, evidentemente, não afasta a possibilidade de se inventariar todo um conjunto de conquistas já sedimentadas e que, em princípio e sem excluírem outras possibilidades, servem como uma espécie de roteiro a guiar o intérprete e de modo geral os órgãos vinculados à concretização dessa garantia do mínimo existencial. 
Assim, verifica-se que ainda há espaço para discussôes no sentido do conteúdo do direito à educação que integra o mínimo existencial, sem, contudo, limitar seu âmbito de proteção a esse conceito, como bem pontua Ximenes (2014). Retoma-se, então, a ideia de que o mínimo existencial é mais um fundamento, mas não o único, para o afastamento da teoria da reserva do possível. Araújo (2013, p. 99) esclarece que "a proteção ao mínimo existencial no âmbito positivo decorre do status de fundamentalidade dos direitos sociais." O núcleo de direitos que compóem o mínimo existencial, portanto, não pode ser atingido pelo Estado ou pela sociedade (SARLET; SAAVEDRA, 2012), motivo pelo qual não lhe é oponível a reserva do possível.

Ademais, o STF, ao reconhecer o direito à Educação Infantil, esclareceu que, tratando-se essa etapa da educaçáo enquanto um dever do Estado, este só se desincumbe do ônus quando propicia o "acesso pleno ao sistema educacional" (BRASIL, 2006, p. 1.534) aos titulares desse direito, possibilitando a judicialização das políticas de Educação Infantil quando da sua não garantia.

\section{As possibilidades de interferência do poder judiciário}

Superada a questão relativa à possibilidade da judicialização das políticas, surge a questão: até que ponto pode o judiciário interferir?

Abramovich (2005) indica que, caso não tenha sido adotada nenhuma medida a fim de assegurar determinada política pública prevista constitucionalmente, cabe ao Judiciário dar ciência da omissão ao Poder competente para que elabore a medida cabível. No sistema de garantias brasileiro (art. 5, LXXI da CF/88) há, inclusive, previsão do instrumento do mandado de injunção, que é a ação cabível "sempre que a falta de norma regulamentadora torne inviável o exercício dos direitos e liberdades constitucionais e das prerrogativas inerentes à nacionalidade, à soberania e à cidadania." (BRASIL, 1988). Contudo, nesse caso, a recente lei 13.300 de 2016, prevê que, não sendo suprimida a mora legislativa no prazo concedido pelo Poder Judiciário, poderá este estabelecer as condições necessárias ao exercício dos direitos, inclusive com efeitos erga omnes, ou seja, a todos que são prejudicados pela ausência da legislação, e não apenas às partes do processo. (BRASIL, 2016b) 
Ao prever a necessária determinação do Judiciário para que o Poder competente implemente a política cabível, Abramovich (2005) ressalta que essa alternativa se justifica no diálogo que deve existir entre os poderes, entendendo que o Judiciário somente está autorizado a suprir a omissáo diretamente nos casos de grave ofensa ou violação aos direitos fundamentais e quando ausente a colaboração dos demais poderes. $\mathrm{O}$ mesmo autor ainda pontua que, nos casos em que apenas há um descumprimento por parte da Administração de obrigaçóes previamente fixadas em lei, não se está diante do controle da política, tratando-se apenas de um caso em que será determinada a aplicação da lei (ABRAMOVICH, 2005), o que também é defendido por Sousa Santos (2011). Nos casos em que o Judiciário estiver diante de atos praticados pelos demais poderes que não estão em conformidade com os fins constitucionais, a solução deveria compreender o reenvio do ato ao Poder competente para a reformulação da política, em virtude do claro sentido político presente nessas decisóes. $\mathrm{Ou}$, ao menos, "estabelecer mecanismos de comunicação, debate e diálogo que lembrem aos Poderes Públicos os compromissos assumidos, forçando-os a incorporar nas prioridades de governo medidas destinadas a cumprir suas obrigaçôes." (ABRAMOVICH, 2005, p. 209) O objetivo, pois, é alcançar com a máxima efetividade a satisfação dos direitos fundamentais sociais.

Contudo, em diversos casos o Judiciário, em lugar de proporcionar esse debate com os demais poderes, tem imposto tutelas específicas: determinaçôes a serem cumpridas apontando a política pública a ser realizada (ZANETI JUNIOR, 2013). Embora haja espaço para essa opção, nem sempre ela é a mais viável. É necessário reconhecer que há limitaçôes, especialmente vinculadas a detalhes técnicos, que não são do âmbito próprio de conhecimento dos magistrados (DANIEL, 2013; CORTEZ, 2013). Ao analisarem as decisóes do STF em demandas relacionadas ao direito à educação, Scaff e Pinto (2016, p. 444) salientaram a falta de "aprofundamento teórico" e do necessário "diálogo com a área educacional” da corte para as decisóes proferidas. Nesse contexto, embora as políticas públicas sejam passíveis de controle pelo Judiciário, cabe a este Poder reconhecer as limitaçôes de sua ingerência frente ao caso concreto (SILVEIRA, 2013), não interferindo no âmbito de discricionariedade dos demais poderes caso essa prerrogativa não tenha sido exercida em afronta aos direitos fundamentais e aos fins constitucionais. O Poder Judiciário somente poderá intervir nas 
políticas públicas caso fique "demonstrada a irrazoabilidade do ato discricionário praticado pelo Poder Público, devendo o juiz pautar sua análise em atenção ao princípio da proporcionalidade." (GRINOVER, 2013, p. 138) Nessa perspectiva, a judicialização da política não deve ser vista como o protagonismo indevido do Poder Judiciário; antes, deve ser analisada sob a ótica do cumprimento dos direitos fundamentais. (ZUFELATO, 2013)

No julgamento da ADPF no 45, na qual se questionava o veto realizado pelo presidente da república à lei de diretrizes orçamentárias, o STF sinalizou seu papel de protetor dos direitos econômicos, sociais e culturais a fim de manter a ordem constitucional. Indicou que cabe ao Judiciário intervir nessas questóes quando há ofensa aos direitos fundamentais previstos constitucionalmente, não obstante não seja sua função própria a formulação e a implementação de políticas públicas. Abordou ainda a questão da reserva do possível, confirmando a tese que não é dado ao Estado imiscuir-se do cumprimento das ordens constitucionais sob a alegação de ausência de recursos, exceto mediante motivo justo e comprovado, especialmente quando é a própria Administração que destina as verbas orçamentárias, como também considerando-se que o orçamento deve ser pensado justamente visando o atingimento dos fins sociais insertos na Constituição (BRASIL, 2004). Referida decisão tem servido de precedente para fundamentar diversas outras decisóes proferidas nas mais variadas instâncias do Poder Judiciário no país.

\section{Consideraçóes finais}

À guisa de conclusão, é possível afirmar que há casos nos quais é permitido ao Poder Judiciário julgar questôes relacionadas às políticas educacionais, notadamente quando a Administração não tem dado efetividade ao direito à educação e, mais especificamente, o direito à Educação Infantil. Contudo, como apontado neste trabalho, há limitaçóes que deverão ser observadas pelo Poder Judiciário para que não substitua a Administração Pública no exercício de sua função constitucional.

Sendo assim, aponta-se a necessidade de pesquisas que se destinem a investigar a interferência do Poder Judiciário na discricionariedade administrativa, investigando quais os limites de suas decisóes, para que não haja 
ingerência indevida e ofensa ao princípio da separação dos poderes. Da mesma forma, pesquisas mais empíricas poderiam averiguar se, de fato, vem ocorrendo o fenômeno da judicialização nas demandas que exigem a consecução do direito à Educação Infantil perante o Poder Judiciário. Isso porque, como apontado neste trabalho, a judicialização é o deslocamento das decisões tomadas tradicionalmente pelos poderes eleitos para o sistema de justiça (TATE; VALLINDER, 1995; BARROSO, 2009; SILVEIRA, 2013), sendo que a aplicação das previsôes legais, sem que haja deslocamento de decisóes políticas para esse Poder, não se configuraria como judicialização (SOUSA SANTOS, 2011). Portanto, afigurar-se-ia relevante investigar em que medida as decisôes do Poder Judiciário envolvendo o direito à Educação Infantil geram judicialização ou apenas a garantia de direitos nos termos previstos em lei.

Essas questôes também abrem espaços para outras pesquisas que possam indicar em que medida a judicialização das políticas educacionais se configura como um fenômeno positivo ou negativo (VICTOR, 2011). É nessa seara que se faz necessário que a litigância do direito à Educação Infantil se dê de forma estratégica (RIZZI; XIMENES, 2012), tendo em vista a existência de casos nos quais as decisóes do Poder Judiciário muitas vezes desconsideram as discussões que são realizadas no campo educacional.

\section{Notas}

1 Na redação original da CF/88 a Educação Infantil era a etapa destinada a atender às crianças com idade entre zero e seis anos. A EC no 53/2006 alterou a faixa etária atendida para a faixa entre zero e cinco anos.

2 As cláusulas pétreas são previstas no art. $60, \$ 4^{\circ}$ da CF/88 e tratam-se de matérias constitucionais que não podem ser abolidas e nem modificadas, mesmo por meio de emendas constitucionais (BRASIL, 1988).

\section{Referências}

ABRAMOVICH, Víctor. Linhas de trabalho em direitos econômicos, sociais e culturais: instrumentos e aliados. SUR - Revista Internacional de Direitos Humanos. Ano 2, número 2, 2005. p. 188-223. 
ARAÚJO, Fernanda Raquel Thomaz de. Controle judicial de politicas públicas e realinhamento da atividade orçamentária na efetivação do direito à educação: processo coletivo e a cogniçáo do judiciário. 2013. 197 f. Dissertaçáo (Mestrado) - Curso de Direito Negocial, Universidade Estadual de Londrina, Londrina, 2013.

BARREIRO, Guilherme Scodeler de Souza; FURTADO, Renata Pedretti Morais. Inserindo a judicializaçáo no ciclo de políticas públicas. Rev. Adm. Pública. Rio de Janeiro, v. 49, n. 2, mar./abr. 2015, p. 293-314.

BARROSO, Luís Roberto. Judicialização, ativismo e legitimidade democrática. Revista Eletrônica de Direito do Estado, n. 18, abr. 2009. Trimestral. Disponível em: <http:// www.oab.org.br/editora/revista/users/revista/1235066670174218181901.pdf>. Acesso em: 19 jan. 2016.

BOBBIO, Norberto. A era dos direitos. Rio de Janeiro: Campus, 1992. Tradução de: Carlos Nelson Coutinho.

BRASIL. Constituição (1988). Constituição da República Federativa do Brasil. Brasília, 5 out. 1988.

BRASIL. Instituto Nacional de Pesquisas Educacionais Anísio Teixeira. Diretoria de estudos educacionais. Relatório do $1^{\circ}$ ciclo de monitoramento das metas do PNE: biênio 2014-2016. Brasília: INEP, 2016a.

BRASIL. Lei federal no 8.069, de 13 de julho de 1990. Estatuto da criança e do adolescente. Rio de Janeiro: Imprensa Oficial, 1990.

BRASIL. Lei federal no 9.394. Estabelece as diretrizes e bases da educação nacional. Brasília, 23 dez. 1996.

BRASIL. Lei federal no 13.300, de 23 de junho de 2016. Disciplina o processo e o julgamento dos mandados de injunçáo individual e coletivo e dá outras providências. Brasília: jun. 2016b.

BRASIL. Lei federal no 13.257, de 8 de março de 2016. Dispóe sobre as políticas públicas para a primeira infância e altera a Lei no 8.069 , de 13 de julho de 1990 (Estatuto da Criança e do Adolescente), o Decreto-Lei no 3.689, de 3 de outubro de 1941 (Código de Processo Penal), a Consolidação das Leis do Trabalho (CLT), aprovada pelo Decreto-Lei no 5.452, de 1o de maio de 1943, a Lei no 11.770, de 9 de setembro de 2008, e a Lei no 12.662, de 5 de junho de 2012. Brasília, 2016c.

Disponível em: <http://www.planalto.gov.br/ccivil_03/_ato2015-2018/2016/lei/113257. htm> Acesso em: 14 mai. 2017.

BRASIL. Supremo Tribunal Federal. Agravo Regimental no Recurso Extraordinário no 410715. Recorrente: Município de Santo André. Recorrido: Ministério Público do Estado de São Paulo. Relator: Ministro Celso de Mello. Brasília, 22 de janeiro de 2005. Diário de Justiça da União. Brasília, 03 fev, 2006. 
BRASIL. Supremo Tribunal Federal. Arguição de Descumprimento de Preceito

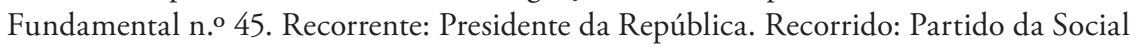
Democracia Brasileira. Relator: Ministro Celso de Melo. Brasília, 29 de abril de 2004. Diário de Justiça da União. Brasília, 04 maio 2004.

BRASIL. Supremo Tribunal Federal. Recurso Extraordinário no 436996. Recorrente: Ministério Público do Estado de São Paulo. Recorrido: Município de Santo André. Relator: Ministro Celso de Mello. Brasília, 26 de janeiro de 2005. Diário de Justiça da União. Brasília, 07 nov. 2005.

CANELA JUNIOR, Osvaldo. O orçamento e a "reserva do possível':

dimensionamento no controle judicial de políticas públicas. In: GRINOVER, Ada Pellegrini; WATANABE, Kazuo. O controle jurisdicional de políticas públicas. 2. ed. Rio de Janeiro: Forense, 2013.

COMPARATO, Fabio Konder. Ensaio sobre o juízo de constitucionalidade de políticas públicas. Revista de Informação Legislativa. Brasília, n. 138, jun. 1998. p. 39-48.

CORRÊA, Luiza Andrade. A judicialização da política pública de educação infantil no Tribunal de Justiça de São Paulo. 2014. 236 f. Dissertação (Mestrado) - Curso de Direito, Universidade de São Paulo. São Paulo, 2014.

CORTEZ, Luís Francisco Aguilar. Outros limites ao controle jurisdicional de políticas públicas. In: GRINOVER, Ada Pellegrini; WATANABE, Kazuo. O controle jurisdicional de políticas públicas. 2. ed. Rio de Janeiro: Forense, 2013. p. 285-307.

CURY, Carlos Roberto Jamil. A educação infantil como direito. In BRASIL. 
FERREIRA FILHO, Manoel Gonçalves. Poder judiciário na constituição de 1988: judicialização da política e politização da justiça. Revista de Direito Administrativo. Rio de Janeiro, v. 198, dez. 1994, p. 1-17.

GRACIANO, Mariângela; MARINHO, Carolina; FERNANDES, Fernanda. As demandas judiciais por educação na cidade de São Paulo. In HADDAD, Sérgio; GRACIANO, Mariângela. A educação entre os direitos humanos. Campinas: Autores Associados, 2006. p. 156-196.

GRINOVER, Ada Pellegrini. O controle jurisdicional de políticas públicas. In: GRINOVER, Ada Pellegrini; WATANABE, Kazuo. O controle jurisdicional de políticas públicas. 2. ed. Rio de Janeiro: Forense, 2013. p. 125-150.

HEUKO, Guilerme Ramon. A efetividade e a atuação judicial na promoção dos direitos sociais prestacionais. In: SAVARIS, José Antonio; Strapazzon, Carlos Luiz (org.). Direitos fundamentais da pessoa humana. Curitiba: Alteridade editora, 2012. p. 357-379.

JACOB, Cesar Augusto Alckmin. A "reserva do possível”: obrigação de previsão orçamentária e de aplicação da verba. In: GRINOVER, Ada Pellegrini; WATANABE, Kazuo. O controle jurisdicional de politicas públicas. 2. ed. Rio de Janeiro: Forense, 2013. p. 237-283.

LOPES, José Reinaldo de Lima. Direito subjetivo e direitos sociais: o dilema do judiciário no estado social de direito. In: FARIA, José Eduardo (org.). Direitos humanos, direitos sociais e justiça. São Paulo: Malheiros Editores, 2002.

MACHADO, L. M.; OLIVEIRA, R. P. de. Direito à educação e legislação do ensino. In: WITTMANN, L. C.; GRACINDO, R. G. o Estado da arte em política e gestão da educação no Brasil: 1991 a 1997, Brasília: ANPAE/Campinas: Editora Autores Associados, 2001.

MARINHO, Carolina Martins. Justiciabilidade dos direitos sociais: análise de julgados do direito à educação sob o enfoque da capacidade institucional. 2009. 120 f. Dissertação (Mestrado) - Curso de Direito, Universidade de São Paulo, São Paulo, 2009.

MARSHALL, Thomas Humphrey. Cidadania e classe social. Rio de Janeiro: Zahar, 1967.

PANNUNZIO, Eduardo. O poder judiciário e o direito à educação. In RANIERI, Nina; RIGHETTI, Sabine. Direito à educação: aspectos constitucionais. São Paulo: Editora da Universidade de São Paulo, 2009. p. 61-88.

PIETRO, Maria Sylvia Zanella di. Direito administrativo. 13. ed. Sáo Paulo: Atlas, 2001.

RIZZI, Ester; XIMENES, Salomão de Barros. Litigância estratégica para a promoção de políticas públicas: as açóes em defesa do direito à educaçáo infantil em São Paulo. In: FRIGO, Darci; PRIOSTE, Fernando; ESCRIVÃO FILHO, Antônio Sérgio. Justiça e direitos humanos: experiências de assessoria jurídica popular. Curitiba: Terra de Direitos, 2010. p. 105-127. 
SADEK, Maria Tereza. Judiciário e arena pública: um olhar a partir da ciência política. In: GRINOVER, Ada Pellegrini; WATANABE, Kazuo. O controle jurisdicional de políticas públicas. 2. ed. Rio de Janeiro: Forense, 2013p. 2-32.

SARLET, Ingo Wolfgang; FIGUEIREDO, Mariana Filchtiner. Reserva do possível, mínimo existencial e direito à saúde: algumas aproximaçóes. In. SARLET, Ingo Wolfgang; TIMM, Luciano Benetti. Direitos fundamentais: orçamento e "reserva do possível”. Porto Alegre: Livraria do Advogado, 2013. p. 13-50.

SARLET, Ingo Wolfgang; SAAVEDRA, Giovani Agostini. Breves notas sobre a garantia do mínimo existencial e os limites materiais de atuação do legislador, com destaque para o caso da Alemanha. In: SAVARIS, José Antonio; STRAPAZZON, Carlos Luiz. Direitos fundamentais da pessoa humana: um diálogo latino-americano. Curitiba: Alteridade editora, 2012. p. 65-88.

SARLET, Ingo Wolfgang. Os Direitos Sociais como Direitos Fundamentais: contributo para um balanço aos vinte anos da Constituição Federal de 1988. 2008. Disponível em: <http:/www.stf.jus.br/arquivo/cms/processoAudienciaPublicaSaude/anexo/artigo_Ingo_ DF_sociais_PETROPOLIS_final_01_09_08.pdf>.Acesso em: 06 jan. 2006.

SCAFF, Elisângela Alves da Silva; PINTO, Isabela Rahal de Rezende. O Supremo Tribunal Federal e a garantia do direito à educação. Revista Brasileira da Educação. Rio de Janeiro, v. 21, n. 65, jun. 2016. p. 431-454.

SILVEIRA, Adriana A. Dragone. A exigibilidade do direito à educação básica pelo Sistema de Justiça: uma análise da produção brasileira do conhecimento. RBPAE, Porto Alegre, v. 24, n. 3, dez. 2008, p. 537-555.

SILVEIRA, Adriana A. Dragone. Conflitos e consensos na exigibilidade judicial do direito à educação básica. Educ. Soc., [s.1.], v. 34, n. 123, p.371-387, jun. 2013. FapUNIFESP (SciELO). DOI: 10.1590/s0101-73302013000200003. Disponível em: <http://www.scielo.br/scielo.php?script=sci_arttext\&pid=S0101-73302013000200003>. Acesso em: 09 jan. 2016.

SILVEIRA, Adriana A. Dragone. Exigibilidade do direito à educação infantil: uma análise da jurisprudência. In. SILVEIRA, Adriana Dragone; GOUVEIA, Andréa Barbosa; SOUZA, Ângelo Ricardo de. Conversas sobre politicas educacionais. Curitiba: Appris, 2014. p. 167-188.

SILVEIRA, Adriana A. Dragone. $O$ direito à educação de crianças e adolescentes: análise da atuação do Tribunal de Justiça de São Paulo (1991-2008). 2010. 303 f. Tese (Doutorado) - Faculdade de Educação da Universidade de São Paulo, São Paulo, 2010.

SILVEIRA, Adriana A. Dragone Possibilidades e limites da judicialização da educação: análise do sistema de justiça do Paraná. Curitiba: UFPR, 2015. 104 p. Relatório técnico.

SOUSA SANTOS, Boaventura de. Para uma revolução democrática da justiça. São Paulo: Cortez, 2011. 
TATE, C. Neal; VALLINDER, Torbjörn. The global expansion of judicial power: the judicialization of politics. In. TATE, C. Neal; VALLINDER, Torbjörn. The Global Expansionof Judicial Power. Nova Iorque: New York Unversity Press, 1995. p. 1-10.

TAYLOR, Matthew M. O judiciário e as políticas públicas no Brasil. Dados Revista de Ciências Sociais, Rio de Janeiro, v. 50, n. 2, 2007, p. 229-257.

VALLINDER, Torbjörn. When the courts go marching in. In. TATE, C. Neal; VALLINDER, Torbjörn. The Global Expansion of Judicial Power. Nova Iorque: New York Unversity Press, 1995. p. 13-26.

VICTOR, Rodrigo Albuquerque De. Judicialização de políticas públicas para a educação infantil: características, limites e ferramentas para um controle judicial legítimo. São Paulo: Saraiva, 2011.

VIOLIN, Jordão. Protagonismo judiciário e processo coletivo estrutural: o controle jurisdicional de decisóes políticas. Salvador: Juspodivm, 2012.

WATANABE, Kazuo. Controle jurisdicional das políticas públicas - “mínimo existencial" e demais direitos fundamentais imediatamente judicializáveis. In: GRINOVER, Ada Pellegrini; WATANABE, Kazuo. O controle jurisdicional de politicas públicas. 2. ed. Rio de Janeiro: Forense, 2013. p. 213-236.

XIMENES, Salomão Barros. Direito à qualidade na educação básica: teoria e crítica. São Paulo: QuartierLatin, 2014.

ZANETI JUNIOR, Hermes. A teoria da separaçáo de poderes e o estado democrático constitucional: funçóes de governo e funçóes de garantia. In: GRINOVER, Ada Pellegrini; WATANABE, Kazuo. O controle jurisdicional de politicas públicas. 2. ed. Rio de Janeiro: Forense, 2013. p. 33-72.

ZUFELATO, Camilo. Controle judicial de políticas públicas mediante açóes coletivas e individuais. In: GRINOVER, Ada Pellegrini; WATANABE, Kazuo. O controle jurisdicional de políticas públicas. Rio de Janeiro: Forense, 2013.2. ed. p. 310-331.

Recebido em 4 dez. 2017 / Aprovado em 20 fev. 2019

\section{Para referenciar este texto:}

TAPOROSKY, B. C. H.; SILVEIRA, A. D. A judicialização das políticas públicas e o direito à educação infantil. EccoS - Revista Científica, São Paulo, n. 48, p. 295-315. jan./mar. 20I9. Disponível em: <https://doi.org/I0.5585/EccoS.n48.8II8>. 
